\title{
OBITUAR Y
}

\section{Charles Matthews Manly}

By the death of Charles Matthews Manly, on October 17 th, at the early age of fiftyrone, ariation has lost one of its most brilliant pioneers.

Charles Matthews Manly will best be remembered in the history of aviation as the engineer assistant to Professor S. P. Langley when the latter was constructing his famous "aerodrome." Manly was appointed Assistant to Langley in June, 3898 . Alter failure to gret an engine of low weight per horse-power built, Manly undertook the construction of such an engine, and in a few months, after two years had been spent in fruitless attempts by other engine designers, Manly produced his first engine of $18 \frac{1}{2}$ h.p. weighing 108 lbs., cooled by wrapping wet cloths round the cylinders. Later, this engine was modified and provided with water jackets and developer $2 \mathrm{I}_{\frac{1}{2}}$ h.p. and weight $\mathrm{z} 20 \mathrm{lbs}$. A final engine was constructed weighing 187.5 lbs. and developing 32.4 h.p. at 950 r.p.m. This was practically the first successful aero engine ever built and was a remarliable advance on any engine of the time.

Charles Manly was a man of great courage and great persistence. He believed in the machine and its engine, and undertook to be the pilot when it was launched on its first disastrous attempt on October $7^{\text {th, }}$ igo3. Lncleterred by the failure of this attempt, in which the pilot fell with the machine into the water, he made a second attempt on December $8 \mathrm{th}, 1903$, with a similar result. As Manly himself wrote afterwards, "I decided to take a chance." How great that chance was every pilot will know, and if any man ever deserved success it was Charles Matthews Manly.

Charles Manly was the inventor of over fifty improvements in connection with motor transport.

He was in advance of his time in many ways and missed a great success by a very small margin. Whatever controversy has arisen over the Langley machine, whatever criticisms may be given of it in the future, Manly's name will always remain as one of the great pioneers who blazed the way towards the success of the aeroplane as it is. 